\title{
TCOM \\ Awareness, views and experiences of Citizen Science among Swedish researchers - two surveys
}

\section{Pavel Bína, Fredrik Brounéus, Dick Kasperowski, Niclas Hagen, Martin Bergman, Gustav Bohlin, Mari Jönsson, Stephen Coulson and Tim Hofmeester}

Abstract

Keywords

DOI
In 2021 Sweden's first national portal for citizen science will be launched to help researchers practice sustainable and responsible citizen science with different societal stakeholders. This paper present findings from two surveys on attitudes and experiences of citizen science among researchers at Swedish universities. Both surveys provided input to the development of the national portal, for which researchers are a key stakeholder group. The first survey $(n=636)$ was exclusively focused on citizen science and involved researchers and other personnel at Swedish University of Agricultural Science (SLU). $63 \%$ of respondents at SLU had heard about citizen science (CS) prior to the survey; however a majority of these $(61 \%)$ had not been involved in any CS initiative themselves.

Dominant reasons for researchers choosing a CS approach in projects were to enable collection of large amounts of data (68\%), improving the knowledge base (59\%), improving data quality (25\%), promote participants' understanding in research $(21 \%)$ and promote collaboration between the university and society $(20 \%)$. The other survey $(n=3699)$ was on the broader topic of communication and open science, including questions on CS, and was distributed to researchers from all Swedish universities. $61 \%$ of respondents had not been engaged in any research projects where volunteers were involved in the process. A minority of the researchers had participated in projects were volunteers had collected data (18\%), been involved in internal or external communication (16\%), contributed project ideas (14\%) and/or formulated research questions $(11 \%)$. Nearly four out of ten respondents $(37 \%)$ had heard about CS prior to the survey. The researchers were more positive towards having parts of the research process open to citizen observation, rather than open to citizen influence/participation. Our results show that CS is a far from well-known concept among Swedish researchers. And while those who have heard about CS are generally positive towards it, researchers overall are hesitant to invite citizens to take part in the research process.

Citizen science; Professionalism, professional development and training in science communication; Science communication in the developing world

https://doi.org/10.22323/2.20060210 


\section{Background}

Researchers at

SLU on CS: to known of is not to be involved
Sweden has a long tradition of collaboration between researchers and citizens, with early examples dating as far back as the 18th century. Currently, citizen science (CS) is gaining in popularity in several research areas in Sweden and is increasingly recognised by policy. The latest Swedish research bill [2020] from the Swedish government recognise CS as necessary to mitigate and address challenges in climate change, sustainable development and societies, migration, integration, antibiotics resistance, welfare and work life. Furthermore to increase the public understanding and trust for science to meet disinformation and knowledge resistance (Prop. 2020/21:60) The Swedish University for Agricultural Sciences (SLU) is a key actor in CS on biodiversity, biology and ecology, coordinating several well-known, long time national projects and initiatives, such as the Swedish Species Observation System (Artportalen).

In 2021, Sweden's first national portal for CS will be launched to help researchers practice sustainable and responsible CS with different societal stakeholders. This paper present findings from two surveys on attitudes and experiences of CS among researchers at Swedish universities. Both surveys provided input to the development of the national portal, for which researchers are a key stakeholder group. The first survey $(n=636)$ was exclusively focused on CS and involved researchers and other personnel at SLU. The other $(n=3$ 699) was on the broader topic of communication and open science, including CS, and was distributed to researchers from all Swedish universities.

Survey participants were allowed to select multiple answers, thus response percentages exceed $100 \% .63 \%$ of respondents at SLU $(n=636)$ had heard about CS prior to the survey; however a majority of these (61\%) had not been involved in any CS initiative themselves (Figure 1). Respondents who had been involved in CS $(n=132)$ had been so as a researcher $(44 \%)$, coordinator $(37 \%)$, volunteer $(22 \%)$, environmental analyst $(21 \%)$, communicator $(11 \%)$, teacher $(7 \%)$ and IT developer ( $2 \%)$. The most common subject areas in these CS projects were nature (71 \%; species, environment, biodiversity), and water (21\%; water quality, fishing). Dominant reasons for researchers choosing a CS approach in the projects were to enable collection of large amounts of data (68\%), improving the knowledge base ( $59 \%$ ), improving data quality ( $25 \%)$, promote participants' understanding in research ( $21 \%)$ and promote collaboration between the university and society (20 $\%)$. The volunteers participating in the CS projects were most commonly the broader public ( $48 \%$ ) and amateur experts ( $48 \%$ ), followed by professionals ( $31 \%$ ) and civil society organisation members $(27 \%)$. Their contributions to the project were made by collecting data (95\%), validating data (26\%), participating in communication activities ( $22 \%)$ and training of volunteers $(17 \%)$.

The biggest challenges for the CS researcher/coordinator, according to the SLU survey respondents, were data quality (37\%), funding ( $29 \%)$, reduced control in 


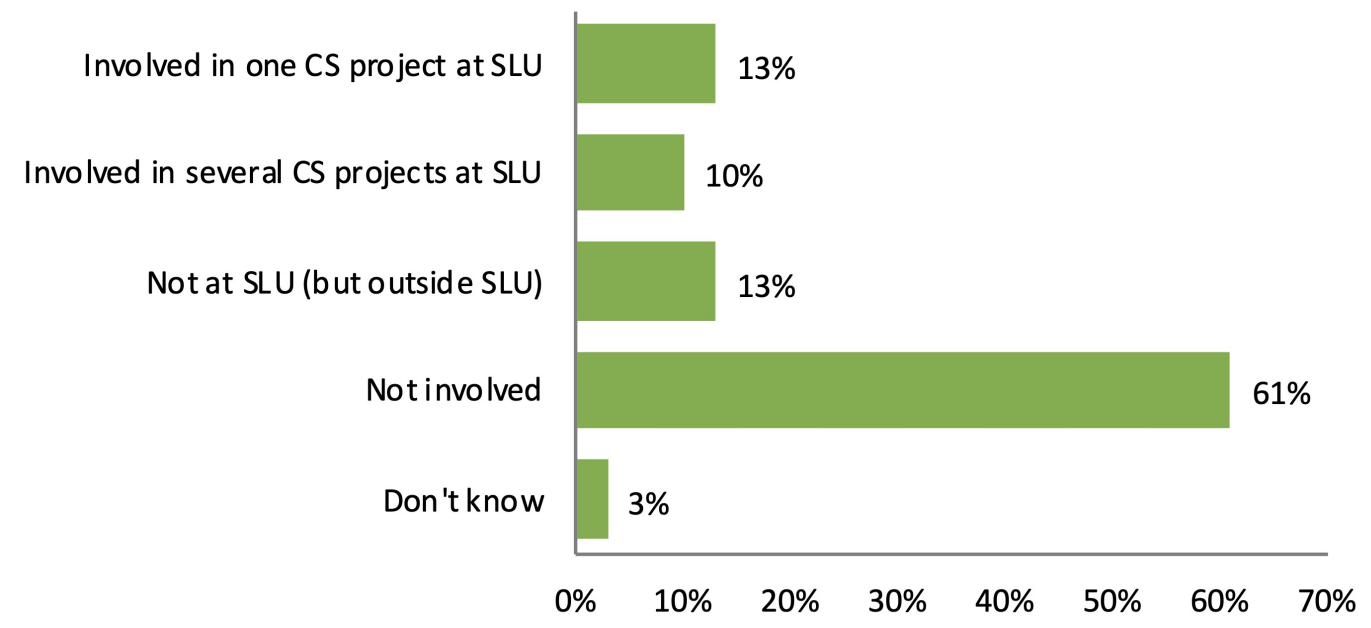

Figure 1. Involvement of respondents at SLU, who have heard about CS ( $n=365)$, in CS projects at SLU and outside SLU.

the scientific process $(25 \%)$, volunteer recruitment (19\%), communication with volunteers $(17 \%)$ and time demands $(16 \%)$. The most beneficial effects of CS as a scientific approach were to enable collection of large amounts of data $(61 \%)$, promote participants' understanding in research (34\%), improve knowledge base $(33 \%)$ and promote participants' understanding in a particular issue $(26 \%)$. The most important ethical aspects to take into account in CS were seen to be transparency in the research process $(53 \%)$, protecting the privacy of participants $(42 \%)$, communication of the results to the volunteers $(41 \%)$, recognition of volunteers' contribution (36\%) and publishing of results as open data (32\%).

National Swedish

survey on

researchers

attitudes to CS:

open science does

not equal

participation
In the second, national, survey with researchers at Swedish universities, respondents were asked about their views on citizens observing or taking part in the research process. The researchers were more positive towards having parts of the research process open to citizen observation, rather than open to citizen influence/participation. While $73 \%$ thought that citizens should be able to observe research prioritizations, only $39 \%$ thought that they should participate. In the conducting of the research (e.g. collection, classification and/or analyses of data), $39 \%$ thought citizens should be able to observe, and $14 \%$ thought they should be allowed to participate. Even in evaluation of on-going research (for example peer review), 39\% thought citizens should be able to observe, and $12 \%$ thought they should be allowed to participate. $82 \%$ thought that citizens should be able to observe use of results (e.g. knowledge, publications, patents), and $53 \%$ thought that they also should participate. Researchers from the arts and humanities were less likely than colleagues from other research areas to agree to citizens participating in the research process.

$61 \%$ of respondents had not been engaged in any research projects where volunteers were involved in the process. A minority of the researchers had participated in projects were volunteers had collected data $(18 \%)$, been involved in internal or external communication $(16 \%)$, contributed project ideas $(14 \%)$ and/or formulated research questions (11\%). Nearly four out of ten respondents $(37 \%)$ 
had heard about CS prior to the survey. A larger proportion of researchers from the natural sciences (51\%) had heard about CS than researchers from other research areas (ranging from 26 to $39 \%$, Figure 2). Among researchers who had heard about CS, $20 \%$ were very positive towards the concept, $42 \%$ were fairly positive; whereas $1 \%$ were very negative and $7 \%$ were fairly negative. $25 \%$ of respondents claimed to be neither negative nor positive. Junior researchers as well as researchers from the natural sciences were more positive towards CS than senior researchers and researchers from the arts and humanities.

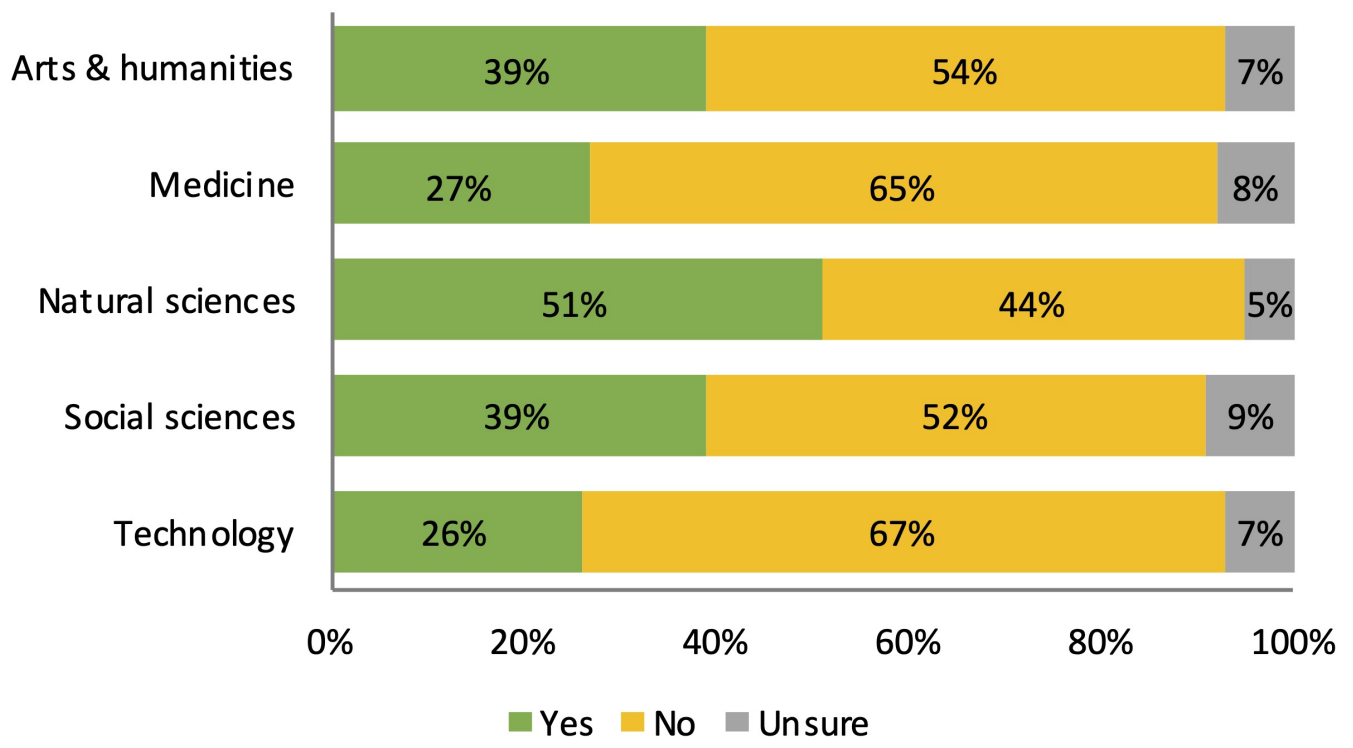

Figure 2. Proportions of researches from different research fields, who have heard about CS. Number of respondents: Arts \& humanities $(n=443)$, Medicine $(n=623)$, Natural sciences $(n=645)$, Social sciences $(n=1211)$, Technology $(n=702)$.

Concluding remarks
Survey results show that CS is a far from well-known concept among Swedish researchers. There seems to be a discrepancy between policy expectations and researchers experience and attitudes of CS. While those who have heard about CS are generally, but cautiously positive towards it, researchers overall are hesitant to invite citizens to take part in the research process. Researchers from the arts and humanities seem to be the most sceptical with regards to involving citizens in their research. If and when citizens are engaged in the research process, it is most likely to help researchers collect data. Data quality is seen as the biggest challenge associated with CS. The input that both surveys provided have been important information in the development of the national portal. Besides offering access to different projects in Sweden and Europe, the portal will also include capacity-building resources for researchers in terms of tools for increasing the capacity to implement high-quality citizen science projects, addressing standardisation and data quality, ethics, implementation of technology, and communication. 
References

Authors
Ministry of Education (17th December 2020). Forskning, frihet, framtid - kunskap och innovation för Sverige. Proposition 2020/21:60. Sweden.

URL: https : / /www .regeringen. se/rattsliga-dokument/proposition/2020/1 2/forskning-frihet-framtid--kunskap-och-innovation-for-sverige/.

Pavel Bína is currently national coordinator for action plans for endangered species at Swedish Environmental Protection Agency. Formerly environmental analyst and researcher at the Swedish Species Information Centre at the Swedish University of Agricultural Sciences (SLU), responsible for volunteer monitoring of Swedish fauna (Fauna guardians) and development of Citizen science forum at SLU. He is particularly interested in citizen engagement in nature and species conservation, quality and validation of citizen science data and its use in biodiversity conservation. E-mail: pavel.bina@slu.se.

Fredrik Brounéus is a researcher and press officer at the Swedish non-profit organisation VA (Public \& Science). Since 2014 he has been involved in a number of national and international citizen science initiatives, and is currently leading VA's work in the two Horizon 2020 projects EU-Citizen.Science and YouCount. Other research interests include media coverage of — and public attitudes to - research and science. E-mail: fredrik@v-a.se.

Dick Kasperowski is professor of Theory of Science at the University of Gothenburg. His interests include citizen science, governance of science, participatory practices in science and the humanities and open collaborative projects in scientific work. The analytical focus of his research concerns how technologies configure relations and the development of epistemic cultures between actors claiming different experiences and knowledge; how political and scientific representations are related and how (scientific) citizenship is connected to research policy, legal and scientific practices.

E-mail: dick.kasperowski@theorysc.gu.se.

Niclas Hagen is researcher in Theory of Science at the University of Gothenburg and has have a broad scientific background with previous studies and research within natural science, social science and humanities. He is currently active in the research project Citizen data: collecting and using data for societal change (funded by Formas). E-mail: niclas.hagen@gu.se.

Martin Bergman is a researcher at VA (Public \& Science). He is conducting studies to better understand the interface between science and society, for example surveys on public attitudes to science and on researchers' views on communication. He is also involved in national and international citizen science projects and other activities to stimulate science communication and public engagement with science. E-mail: martin@v-a.se.

Gustav Bohlin is a researcher working at the Swedish non-profit organization VA (Public \& Science) since 2017 and an affiliated researcher at the Department for Learning, Informatics, Management and Ethics (LIME) at Karolinska Institutet. He holds a PhD in Science Education from Linköping University. His research interests encompass scientific literacy, public understanding of- and attitudes to science as well as researchers' attitudes to communication. E-mail: gustav@v-a.se. 
Mari Jönsson is a researcher at the Swedish Species Information Centre (Artdatabanken) at the Swedish University of Agricultural Sciences (SLU). Her research interests include biological conservation, forest ecology and citizen science. She is particularly interested in citizen engagement in biological recording and the use of citizen science data for answering basic and applied questions about biodiversity and conservation in science and society. E-mail: mari.jonsson@slu.se.

Stephen J. Coulson is currently professor and head of the Department of Arctic Biology at the University Centre in Svalbard (UNIS). Formerly project manager of the Swedish Species Observation System (Artportalen) at the Swedish Species Information Centre (Artdatabanken) at the Swedish University of Agricultural Sciences (SLU). His research interests include ecology of terrestrial polar invertebrates including Arctic biogeography, overwintering strategies, and plant/insect interactions as well as promoting citizen scientists and the use of citizen science data in the scientific process. E-mail: stevec@unis.no.

Tim Hofmeester is a researcher at the Department of Wildlife, Fish, and Environmental Studies at the Swedish University of Agricultural Sciences (SLU). His research focusses on the use of technology, such as camera traps and acoustic recorders, in combination with community science to study human-wildlife coexistence. His study systems range from cities to boreal forests and savannahs and he has a soft spot for small carnivores. With his work, Tim strives to provide knowledge for evidence-based wildlife management.

E-mail: tim.hofmeester@slu.se.

How to cite

(C) The Author(s). This article is licensed under the terms of the Creative Commons Attribution - NonCommercial — NoDerivativeWorks 4.0 License. ISSN 1824-2049. Published by SISSA Medialab. jcom.sissa.it 